\title{
Intellectual disability-hyperkinetic movement-truncal ataxia syndrome
}

INSERM

\section{Source}

INSERM. (1999). Orphanet: an online rare disease and orphan drug data base. Intellectual disability-hyperkinetic movement-truncal ataxia syndrome. ORPHA:369847

A rare, genetic, syndromic intellectual disability disease characterized by global developmental delay, microcephaly, mild to moderate intellectual disability, truncal ataxia, trunk and limb, or generalized, choreiform movements, and elevated serum creatine kinase levels. Variably associated features include mild cerebral atrophy, muscular weakness or hypotonia in early childhood, and/or seizures. Ocular abnormalities (e.g. exophoria, anisometropia, amblyopia) have been reported. 